\title{
Homing behaviour and individual identification of the pipefish Nerophis lumbriciformis (Pisces; Syngnathidae): a true intertidal resident?
}

\author{
Nuno Miguel Monteiro ${ }^{\mathrm{a}, \mathrm{b}, *}$, Maria da Natividade Vieira ${ }^{\mathrm{a}, \mathrm{b}}$, Vitor Almada ${ }^{\mathrm{c}}$ \\ ${ }^{a}$ Departamento de Zoologia e Antropologia, Faculdade de Ciências da Universidade do Porto, Praça Gomes Teixeira, \\ 4099-002 Porto, Portugal \\ ${ }^{\mathrm{b}}$ Centro Interdisciplinar de Investigação Marinha e Ambiental, Rua dos Bragas, 289, 4050-123 Porto, Portugal \\ ${ }^{\mathrm{c}}$ Instituto Superior de Psicologia Aplicada, Rua Jardim do Tabaco, 34, 1149-041 Lisboa, Portugal
}

Received 23 June 2004; accepted 22 October 2004

\begin{abstract}
Syngnathids have been the focus of growing interest due to their peculiar reproductive biology and vulnerability to environmental degradation and overcollecting. In this study, near the south limit of the species' geographic distribution, a description of the homing behaviour of the worm pipefish, Nerophis lumbriciformis, based on the unique facial pigmentation patterns, is presented. Even though the amount of facial pigmentation was substantially higher in larger adult females, suggesting that it can be part of the secondary sexual repertoire of this sex role reversed species, this technique allowed for the positive identification of adult individuals (males and females) during at least 19 months. Recaptures showed that this pipefish shows a strong homing behaviour, with individuals being regularly captured within less than $2 \mathrm{~m}$ of the original identification event. The absence of horizontal migrations to adjacent areas and the observation of adults in the subtidal, together with the overall low number of recaptures (even though some individuals were cyclically resighted) highlighted the fact that the intertidal is not $N$. lumbriciformis' permanent residence. This observation also demonstrates that the estimation of the population size, important for conservation purposes, based solely on intertidal data can be misleading because captured individuals are only a fraction of a larger, mainly subtidal, population.
\end{abstract}

(c) 2004 Elsevier Ltd. All rights reserved.

Keywords: Nerophis lumbriciformis; Syngnathidae; homing behaviour; intertidal; individual identification; facial pigmentation

\section{Introduction}

The physical, chemical and biotic fluctuations of the intertidal environment cause motile species, such as fish, to seek shelter or abandon the area until favourable conditions are restored. Whichever strategy is employed, these responses impose periodicity on individual

\footnotetext{
* Corresponding author. Departamento de Zoologia e Antropologia, Faculdade de Ciências da Universidade do Porto, Praça Gomes Teixeira, 4099-002 Porto, Portugal.

E-mail address: nmonteir@fc.up.pt (N.M. Monteiro).
}

movements (Gibson, 1992, 1999) and force species to alter their microhabitat locations on a tide-related basis.

Syngnathids (pipefishes, seahorses and seadragons) have been the focus of growing interest not only due to their peculiar reproductive biology (Berglund et al., 1989; Vincent, 1994; Jones et al., 1999) but also by an increasing awareness of their vulnerability to environmental degradation and overcollecting (Vincent, 1995; Lourie et al., 1999).

The worm pipefish, Nerophis lumbriciformis (Jenyns, 1835), one of the smallest of endemic western European 
pipefish, is mainly found in rocky reefs from the intertidal down to about $30 \mathrm{~m}$ (Wheeler, 1969; Dawson, 1986) and also occurs in estuaries (Almeida, 1994). It can be found from the Atlantic coast of Norway to the Kattegat, and from Belgium southwards to Morocco (Dawson, 1986). It feeds on small crustaceans (copepods, amphipods and isopods) sucking them through its characteristically upwards pointing snout. Parental care is exclusively paternal and throughout gestation males brood their offspring attached to their flattened ventral surface (Monteiro et al., 2002a). The newborn juveniles are free-swimming and no further care is provided (Monteiro et al., 2003). Previous studies showed that $N$. lumbriciformis displays very specific spatio-temporal patterns of movement, synchronising with the ebb of the tide its major displacements from its preferred high tide substratum, algae, to the protection of the undersurface of boulders (Monteiro et al., 2002b). Apart from these microhabitat shifts, there is no information concerning the dimensions of the home range in this pipefish and its ability to periodically return to a specific location, as is known for many intertidal fish species [e.g. Parablennius sanguinolentus (Santos, 1986), Lipophrys pholis, Ciliata mustela, Acanthocottus bubalis (Gibson, 1967)]. In order to study movement patterns, suitable markings that will allow the recognition of individuals are needed to gather information from successive encounters. Numerous marking methods have been developed, tested and, in the particular case of intertidal fishes, a wide variety of associated problems arise (Moring, 1990; Gibson, 1999). The cryptic nature of their coloration, small body size and the topographic complexity of their habitat, together with the mechanical forces to which rocky intertidal fishes are subjected, impose serious limitations on the types of tags that can be used in studies involving successful recaptures. Natural markings have also been used for individual identification (Connolly et al., 2002; Ottensmeyer and Whitehead, 2003) and, as a nonintrusive method, may present several advantages. Nevertheless, its usage depends on careful preliminary observations that will allow for the correct choice of the measured character, demonstration of the stability of that candidate character over a certain time-period and of its uniqueness in each individual.

Marking of small intertidal pipefish such as Nerophis lumbriciformis has proved to be specially challenging due to its small body size ( 15 and $14 \mathrm{~cm}$ for females and males, respectively), no relief between dermic rings, and absence of caudal, spiny dorsal, pectoral and pelvic fins. In this study, the results of a 19-month investigation on homing behaviour and site fidelity in $N$. lumbriciformis are presented, based on the individual patterns of facial pigmentation. The population studied in this paper is located in North-west Portugal, near the southern limit of the species distribution, and may be vulnerable to environmental changes, especially global warming
(Monteiro et al., 2001) and habitat reduction (Eurosion, pers. comm.).

\section{Methods}

To assess the efficiency of the use of facial markings of Nerophis lumbriciformis, preliminary observations were conducted in aquaria. Thirty aquarium fishes were photographed and observed regularly during a one-year period to determine the stability of the facial markings as a reliable individual character. Using markings on just one side of the head, these individuals ( 15 males and 15 females) were still easily recognizable at the end of the year. It was thus assumed that the technique was sufficiently reliable to be used in the study of this species in the wild.

Regular visits were conducted, from June 2002 to December 2003, to an intertidal rocky shore area of Viana do Castelo $\left(41^{\circ} 41.17 \mathrm{~N} ; 8^{\circ} 50.35 \mathrm{~W}\right)$, North-west Portugal, to follow what seemed to be one of the most stable worm pipefish populations in the Portuguese coast (Monteiro, personal observation). This semi-exposed rocky shore (Nerophis lumbriciformis' populations are very hard to find in exposed shores, at least in the Portuguese Coast) is mainly characterized both by a great number of boulders, which form intricate galleries, and its large diversity of seaweed species, namely brown (e.g. genus Laminaria, Dyctiota, Bifurcaria, Saccorhiza, Himanthalia) and red algae (e.g. genus Mastocarpus, Gelidium, Chondrus, Ceramium, Pterocladia).

Two sections of the rocky coast, approximately $50 \mathrm{~m}$ apart, were chosen (Area $1 \approx 180 \mathrm{~m}^{2} ;$ Area $2 \approx 250 \mathrm{~m}^{2}$ ) and several metallic marks were set in the rock, in a row parallel to the coast line, with the help of a pneumatic rotary hammer. The distances between these fixed coordinates were measured in order to triangulate the exact position of every fish in each study area and so determine the minimum distance travelled between captures. On each visit, a thorough examination of the undersurface of boulders, rockpools and crevices was carried out during low tide, throughout the entire sampling Area 1 trying to minimize possible changes in the relief. Area 2 was sampled to investigate specifically if fishes formerly captured in sampling Area 1 could undergo displacements of more than $50 \mathrm{~m}$ into Area 2 (or vice versa). In the surroundings of the two sampled areas (formerly used for rearing crustaceans), no boulders were present and, consequently, only very few Nerophis lumbriciformis have been observed since the beginning of the monitoring of this population in 1998.

Fishes were captured by hand, measured to the nearest millimetre and digitally photographed on both sides of the head. After release on the exact location, the distances to the two closest coordinates were recorded. 
Fish handling had to be quick and efficient since a prolonged manipulation of this pipefish is stressful, provoking accelerated desiccation, which may lead to the death of the individual (Monteiro, personal observation). Since these fish are easily sexed (see Monteiro et al., 2001), image comparisons were performed within each sex, among individuals of similar size (e.g. the image of a $12-\mathrm{cm}$ female was compared with all previous images of females whose length ranged from 11 to $13 \mathrm{~cm})$. To test if the same fish could be individually identified on different occasions, photographs taken on each visit to the study site were compared with those collected in previous visits by three independent observers. Photos were classified as belonging to the same individual if the three observers agreed on the match of the new photo with an already existing one.

Fish less than $9 \mathrm{~cm}$ were classified as juveniles. Up to this size males lack the ventral incubating area and females in this category never had mature eggs or showed spawning behaviour (Monteiro et al., 2002a). As small individuals almost lacked facial markings, juveniles could not be identified.

Images were taken using a Nikon Coolpix 995, transferred to a PC computer, and the image analysis and manipulation was carried out using a standard image processing software package. An example of the coloration patterns usually displayed by males and females is represented in Fig. 1. An index of facial pigmentation was computed as the percentage of the entire (left and right) facial area (sum of the white and black areas, see Fig. 1(1-3)) occupied by the bright facial spots (marked in white, see Fig. 1(1-3)). These calculations were conducted using UTHSCSA Image Tool 3.0 (University of Texas Health Science Center). Statistical analyses were conducted using Statistica 6.1 (StatSoft). An index of facial pigmentation symmetry was computed as follows: after a mirror transformation, left and right images of the facial areas were superimposed and the area for which both sides coincided in pigmentation was expressed as a percentage of the combined area of both images. An index of 100 would be scored if the pigmentation area of both sides matched each other exactly. A one sample $t$-test was performed to access the level of asymmetry of the samples, comparing the computed values against the theoretical value of 100 .

Using the fixed shore coordinates described above, the distance of the points of capture to the row of metallic marks was compared (with a Mann-Whitney $U$ test), to test for the possibility of males and females differing in vertical distribution patterns.

Differences in facial pigmentation between adult males and females of different size classes were assessed using a factorial ANOVA (males bigger and smaller than $11 \mathrm{~cm}$; females bigger and smaller than $12 \mathrm{~cm}$ ). Data were normal (Shapiro $W=0.950, p>0.05$ ) and variances homogeneous (Levene test, $p>0.05$ ). These values $(12$ and $11 \mathrm{~cm}$, selected for females and males, respectively) were selected since it was observed that larger females, usually bigger than $12 \mathrm{~cm}$, seemed to be more brightly coloured and presented also a larger abdomen (keel-like structure). Since males are $1 \mathrm{~cm}$ shorter than females (Dawson, 1986; Monteiro et al., 2001), it was decided to test if a significant difference was also visible in male facial pigmentation.

The number of adults was estimated using "Jolly" (version 10/07/88 by James E. Hines), based on capturerecapture data (see Seber, 1982).

\section{Results}

During the 19-month survey, a total of 257 fish were captured on 16 field visits (average captures $=16.1$ fish per visit, s.d. $=10.6$; range $=7-43$ ): 94 juveniles and 159 adults (840 and 75\%). Thirty-three recapture events were registered $\left(17 \delta^{\star}\right.$ and $16 \%$; average recapture time $=102$ days; s.d. $=86.89$; range $=14-412$ ). Some individuals were caught more than once, so the total number of distinct adult fish collected was 133 and the number of distinct fish recaptured was 26 (120 and 149). There were no significant differences between the recapture rates of males and females either for the total number of recaptures $\left(\chi^{2}\right.$ goodness of fit test; $\chi^{2}=0.023$; d.f. $=1 ; p=0.865$ ) or for the number of distinct fishes recaptures $\left(\chi^{2}\right.$ goodness of fit test; $\chi^{2}=0.56$; d.f. $=1$; $p=0.456)$.

Capture locations recorded for males and females were scattered along the suitable areas in the rocky intertidal (generally underneath boulders and, less often, in rockpools), with no obvious difference in the distribution pattern between the sexes in terms of distance from the shore (Mann-Whitney $U$ test; $N_{1}=75, N_{2}=88 ; U=3096.5 ; Z=-0.677 ; p=0.498$ ).

The maximum distance between re-sightings was less than $2 \mathrm{~m}(N=33$; average $=0.63 \mathrm{~m} ;$ s.d. $=0.47 \mathrm{~m}$; range $=0.11-1.88 \mathrm{~m}$ ). A particular male, resighted 412 days after the "first identification" event, was found only $21 \mathrm{~cm}$ away from the first capture site.

Capture and recapture calculations, using the JollySeber capture-recapture model for open populations on the complete data set gave a final result of 72 adult individuals, which corresponds to an approximate density of 0.4 fish $\mathrm{m}^{-2}$. This value is significantly higher than the observed density of individuals captured during field samplings (one sample $t$-test of means against "Population density results"; $N=16$; Mean $=0.089$; s.d. $=0.058 ; p<0.001$ )

Even though some coloration spots became more or less vivid over time, the overall pattern, analysed for both sides of the head, allowed accurate identifications of adult fish, as assessed by the independent observers. Coloration patterns differed markedly between the two 

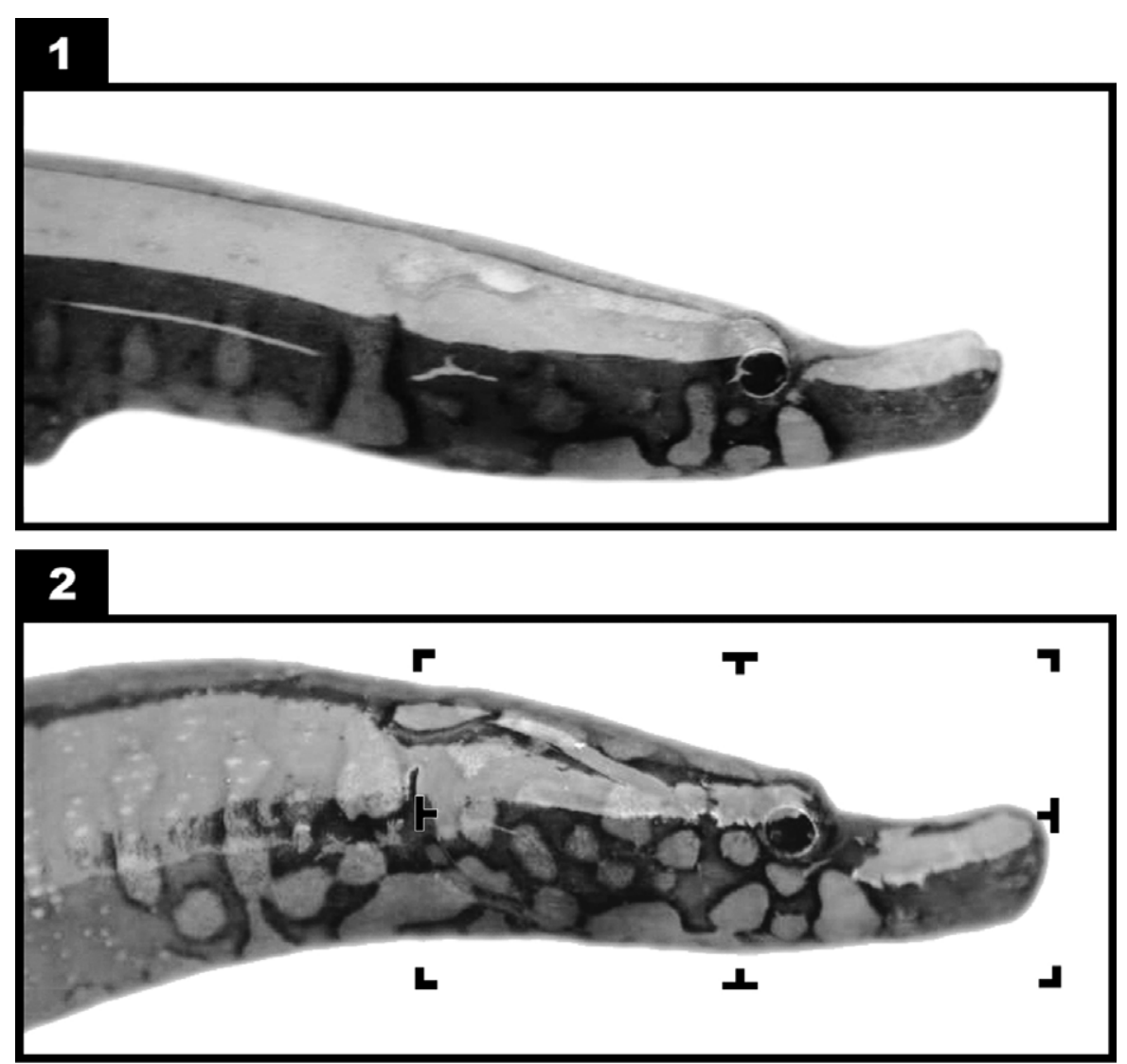

\section{3}

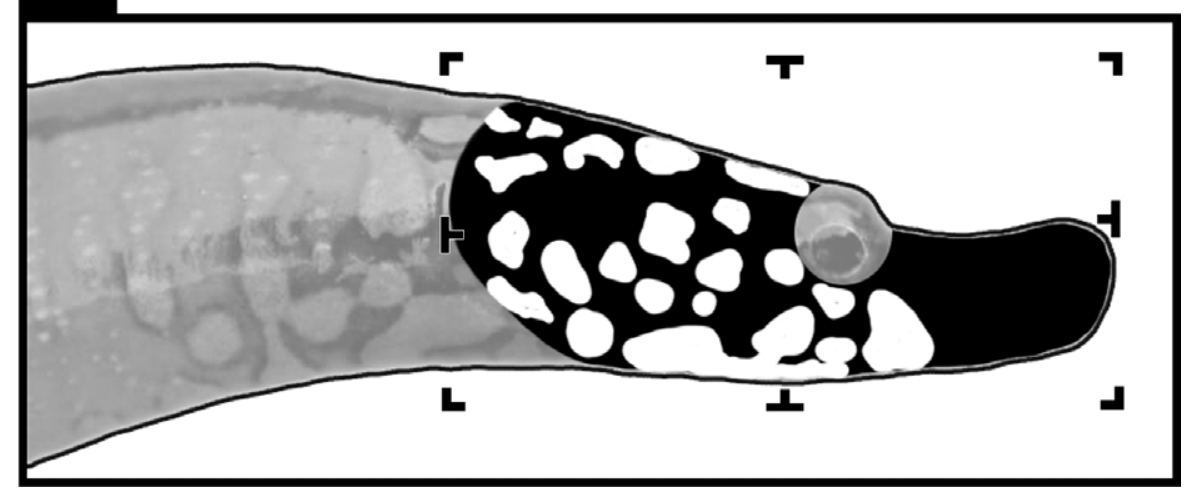

Fig. 1. Facial pigmentation in adult $N$. lumbriciformis ( 1 - male; 2 - female; 3 - head region used for individual recognition and determination of the index of facial pigmentation. See text for a description of this index).

sides of the head (one sample $t$-test of means against "total symmetry"; $N=10$; Mean $=46.9$; s.d. $=10.213$; $p<0.001$ ), so that a doubtful identification based on the facial markings displayed on one side of the head could be confirmed by checking the other side. This asymmetry is especially useful for male identification since they present a lower number of facial markings, when compared to big females (i.e. females bigger than $12 \mathrm{~cm}$; see Fig. 2). Male pigmentation index was similar among individuals bigger and smaller than $11 \mathrm{~cm}$, and did not differ significantly from the pigmentation values of adult females smaller than $12 \mathrm{~cm}$ (Table 1). Larger females presented significantly higher pigmentation indexes (Newman-Keuls post hoc test, data not shown; Fig. 2) mainly due to a greater number of spots in the operculum region (see Fig. 1).

\section{Discussion}

\subsection{The usefulness of facial markings}

The unique facial markings obviate the need to apply physical tags, also eliminating some of the stress that individuals would otherwise undergo when being 


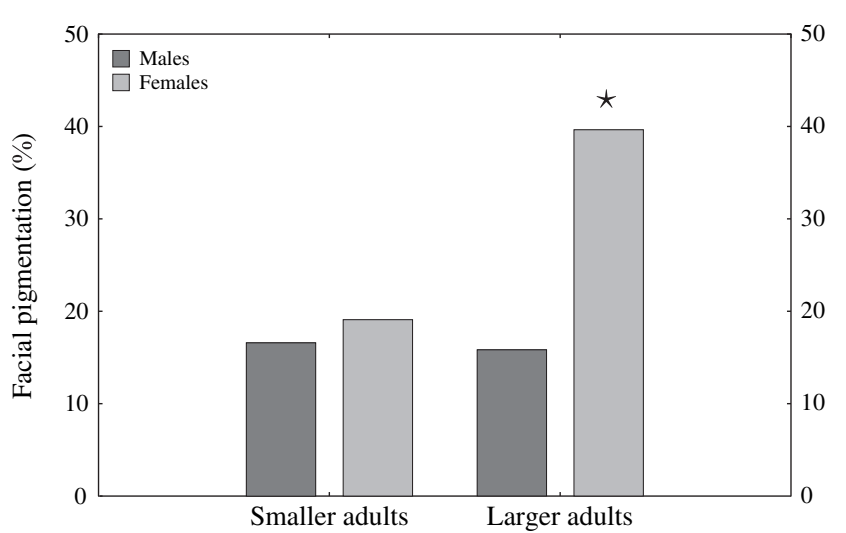

Fig. 2. Average facial pigmentation percentage in adult Nerophis lumbriciformis of different size classes (star shows significant differences in the percentage of facial pigmentation observed in larger females).

manipulated. Furthermore, both in the preliminary aquarium observations, and in wild fish, individuals were identifiable for more than one year. Due to the high level of asymmetry measured on both sides of the face, this recognition technique could be interpreted as "double-marking" since if the analysis of the coloration patterns on one side of the head is inconclusive (e.g. ambiguous pattern or low quality photographs), the other side of the head can be used. This feature is especially useful for the identification of males since, contrary to big females, they present low percentages of facial markings in the head. It should be stressed that this recognition technique is not suitable for the identification of juveniles [4-8 $\mathrm{cm}$ (recruiting size and approximate minimum size for sex determination, respectively)] because they show extremely low levels, or complete absence, of facial pigmentation. Juvenile coloration is somewhat different from adult coloration, basically consisting of a uniform red/brown pigmentation that completely blends with the red algae background. Facial markings seem to appear at the onset of sexual maturity, and further develop, by the addition of new spots, with the preservation of the initial pattern. In the particular case of females, this phenotypic character may also be part of the natural repertoire of secondary sexual characters, such as the presence of a keel-like structure and the stripes along the middle region of the body which may change both in intensity and area under nervous control (Berglund et al., 1997).

Table 1

ANOVA results on the head pigmentation of Nerophis lumbriciformis males and females of different size classes

\begin{tabular}{llcll}
\hline Effects & SS & d.f. & $F$ & $p$ \\
\hline Sex (males vs females) & 1867.32 & 1 & 49.35 & $<0.001$ \\
Size (larger vs smaller) & 1076.41 & 1 & 28.45 & $<0.001$ \\
Sex $\times$ size & 1038.97 & 1 & 27.46 & $<0.001$ \\
Residual & 1362.12 & 36 & & \\
Total & 5344.82 & 39 & & \\
\hline
\end{tabular}

Syngnathids include many endangered species and data on the biology of their populations are critically important for their conservation. Many marking techniques currently used in other fish groups are not easily applicable to syngnathids without serious negative side effects (Woods and Martin-Smith, 2004). Natural markings are known to be present in other species (e.g. Nerophis ophidion, Entelurus aequoreus, Syngnathus acus) and should be explored as a non-intrusive means of individual identification. Facial pigmentation in the seadragon Phycodurus eques proved to be a more reliable identifier than leafy appendages even though this species presents much less facial pigmentation (Connolly et al., 2002).

\subsection{Site fidelity and homing}

Recaptured fishes were invariably found less than $2 \mathrm{~m}$ away from the site of first collection, suggesting a very precise homing capability. The recapture rate was, however, rather low, indicating that, on each visit, only a small proportion of the previously identified fish were present.

Could the low recapture rate be due to inefficient collection and/or small movements of the fish to adjacent sites (e.g. from Area 1 to Area 2)? The data allow for the rejection of these two hypotheses. Not a single fish first collected in Area 1 was recaptured in Area 2, or vice versa. Also, the capture locations were not isolated sites but were included in a broader area that was systematically surveyed. Thus, the possibility of a fish moving to an adjacent pool may also be ruled out. Furthermore, several of the locations where fishes were recaptured had no shelters or crevices where the fish could have escaped detection. For instance, in flat pools where all the boulders were removed during an inspection, no hiding places remained available, so the scanning process was complete and no fish could have escaped collection. Homing is not synonymous with permanent residence on a given site. A fish may use a more or less developed network of passways and shelter sites that it regularly visits, without being permanently attached to any one of them. Most studies on homing of rocky intertidal fishes indicate that although fish often return to a specific location, they are not usually exclusively attached to that location (Gibson, 1967, 1982, 1999; Almada et al., 1983). Studies of agonistic behaviour of rocky intertidal fish indicate that strict territoriality is rare except for breeding males (Gonçalves and Almada, 1998; Faria and Almada, 2001a,b). Defaunation experiments conducted in tidepools commonly showed that, in periods that range from a few days to a few weeks or months, the pools are recolonized not only by new recruits but by larger fish moving from adjacent areas (Faria and Almada, 1999). With the sampling strategy used, the possibility that 
fishes could have moved to nearby intertidal locations can be excluded (both areas were surveyed systematically and no suitable intertidal habitat were available in the surroundings). The logical conclusion seems to be that Nerophis lumbriciformis is not a rocky intertidal resident fish but rather a fish that probably spends most of its time in the subtidal [it is found as deep as $30 \mathrm{~m}$, as stated by Dawson (1986) and Wheeler (1969), and as observed (by scuba diving) in the adjacent subtidal area (Monteiro, personal observation)], making some visits to the rocky intertidal, often to very precise locations.

The ability to return to a very specific location on a regular basis has been previously demonstrated in at least two syngnathids, Corythoichthys haematopterus (Matsumoto and Yanagisawa, 2001) and Hippocampus comes (Perante et al., 2002).

The microhabitat occupied by Nerophis lumbricifor$m i s$ in the rocky intertidal (mainly boulders of different sizes laid above a rock and mud substratum) is a periodically changing environment. During winter months, storms cause drastic alterations to the boulder distribution. These alterations suggest that boulders cannot be the clues used by fish in order to return to very specific locations. Either they use broader landmarks of the topography of the rocky shore, or they rely on navigation processes to orient their movements, as seen in the three-spine stickleback (Odling-Smee and Braithwaite, 2003). Aquarium observations showed that juveniles, adult males and females explore the natural surroundings as soon as the water level in the aquaria starts to decrease, only then choosing a suitable position underneath boulders (Monteiro et al., 2002b). Moreover, during field excursions, it was possible to see that once the fish is spotted underneath a rock or in a particular crevice, if not immediately captured, it tends to move directly to another shelter, in a straightforward and apparently predetermined way. Unlike the rapid and sometimes erratic movements of other fish species found in the intertidal, such as Ciliata mustela, this behaviour suggests a clear knowledge of the topographic nature of the surroundings. The use of topographic information is widespread in several intertidal fish of different families, such as blennids (Almada et al., 1983) and gobids (Griffiths, 2003).

To develop effective strategies for the conservation of intertidal fauna, it is essential to establish the movement patterns and habitat characteristics of the considered species, as well as the actual size of the populations. In the case of Nerophis lumbriciformis, the estimation of population size may change radically, depending on the pattern of use of the rocky intertidal made by this species. The individuals found in the intertidal at any given time may be only a fraction of a larger population. If some of the fish do not usually visit the intertidal, estimations based only on intertidal samples may be profoundly misleading. Thus, a more complete de- termination of home ranges is necessary, essentially integrating data from the distribution in the subtidal area, if this potentially vulnerable species is to be properly conserved.

\section{References}

Almada, V., Dores, J., Pinheiro, A., Pinheiro, M., Santos, R.S., 1983. Contribuição para o estudo do comportamento de Coryphoblennius galerita (L.) (Pisces: Blenniidae). Memórias do Museu do Mar Série Zoológica 2, 1-166.

Almeida, A.J., 1994. Macrofauna acompanhante de zosteráceas. Importância na conservação do meio marinho. Arquivos do Museu Bocage, 125-144.

Berglund, A., Rosenqvist, G., Bernet, P., 1997. Ornamentation predicts reproductive success in female pipefish. Behavioural Ecology and Sociobiology 40, 145-150.

Berglund, A., Rosenqvist, G., Svensson, I., 1989. Reproductive success of females limited by males in two pipefish species. American Naturalist 133, 506-516.

Connolly, R.M., Melville, A.J., Keesing, J.K., 2002. Abundance, movement and individual identification of leafy seadragons, Phycodurus eques (Pisces: Syngnathidae). Marine and Freshwater Research 53, 777-780.

Dawson, C.E., 1986. Syngnathidae. In: Whitehead, P.J.P., Bauchot, M.L., Hureau, J.C., Nielsen, J., Tortonese, E. (Eds.), Fishes of the North-Eastern Atlantic and The Mediterranean. Unesco, Paris, pp. 628-639.

Faria, C., Almada, V.C., 1999. Variation and resilience of rocky intertidal fish in western Portugal. Marine Ecology Progress Series 184, 197-203.

Faria, C., Almada, V., 2001a. Agonistic behaviour and control of access to hiding places in two intertidal blennies, Lipophrys pholis and Coryphoblennius galerita (Pisces: Blenniidae). Acta Ethologica 4, 51-58.

Faria, C., Almada, V.C., 2001b. Microhabitat segregation in three rocky intertidal fish species in Portugal: does it reflect interspecific competition? Journal of Fish Biology 58, 145-159.

Gibson, R.N., 1967. Studies on the movements of littoral fish. Journal of Animal Ecology 36, 215-234.

Gibson, R.N., 1982. Recent studies on the biology of intertidal fishes. Oceanography and Marine Biology: An Annual Review 20, 363 414.

Gibson, R.N., 1992. Tidally-synchronised behaviour in marine fishes. In: Ali, M.A. (Ed.), Rhythms in Fishes. NATO Scientific Affairs Division, Brussels, pp. 63-81.

Gibson, R.N., 1999. Movement and homing in intertidal fishes. In: Horn, M.H., Martin, K.L.M., Chotkowski, M.A. (Eds.), Intertidal Fishes. Life in Two Worlds. Academic Press, London, pp. 97-125.

Gonçalves, E.J., Almada, V., 1998. A comparative study of territoriality in intertidal and subtidal blennioids (Teleostei, Blennioidei). Environmental Biology of Fishes 51, 257-264.

Griffiths, S., 2003. Homing behaviour of intertidal rockpool fishes in south-eastern New South Wales, Australia. Australian Journal of Zoology 51, 387-398.

Jones, A.G., Rosenqvist, G., Berglund, A., Avise, J.C., 1999. The genetic mating system of a sex-role reversed pipefish (Syngnathus typhle): a molecular inquiry. Behavioural Ecology and Sociobiology 46, 357-365.

Lourie, S.A., Vincent, A.C.J., Hall, H.J., 1999. Seahorses: An Identification Guide to The World's Species and Their Conservation. Project Seahorse, London, UK, 213 pp.

Matsumoto, K., Yanagisawa, Y., 2001. Monogamy and sex role reversal in the pipefish Corythoichthys haematopterus. Animal Behaviour 61, 163-170. 
Monteiro, N.M., Almada, V.C., Santos, A.M., Vieira, M.N., 2001. The breeding ecology of the pipefish Nerophis lumbriciformis and its relation to latitude and water temperature. Journal of the Marine Biological Association of the United Kingdom 81, 1031-1033.

Monteiro, N.M., Vieira, M.N., Almada, V.C., 2002a. The courtship behaviour of the pipefish Nerophis lumbriciformis: reflections of and adaptation to intertidal life. Acta Ethologica 4, 109-111.

Monteiro, N.M., Vieira, M.N., Almada, V.C., 2002b. Activity rhythms and cyclical changes in microhabitat preferences in the intertidal pipefish Nerophis lumbriciformis (Pisces: Syngnathidae). Acta Ethologica 5, 39-43.

Monteiro, N.M., Almada, V.C., Vieira, M.N., 2003. Early life history of the pipefish Nerophis lumbriciformis (Pisces: Syngnathidae). Journal of the Marine Biological Association of the United Kingdom 83, 1179-1182.

Moring, J.R., 1990. Marking and tagging intertidal fishes: review of techniques. American Fisheries Society Symposium 7, 109-116.

Odling-Smee, L., Braithwaite, V.A., 2003. The influence of habitat stability on landmark use during spatial learning in the threespined stickleback. Animal Behaviour 65, 701-707.
Ottensmeyer, C.A., Whitehead, H., 2003. Behavioural evidence for social units in long-finned pilot whales. Canadian Journal of Zoology 811, 1327-1338.

Perante, N.C., Pajaro, M.G., Meeuwig, J.J., Vincent, A.C.J., 2002. Biology of seahorse species, Hippocampus comes in the central Philippines. Journal of Fish Biology 60, 821-837.

Santos, R.S., 1986. Capacidade de retorno à área vital, padrão de dispersão e organização social em Blennius sanguinolentus Pallas (Pisces: Blenniidae) durante a época de reprodução. Arquipélago, Série de Ciências Naturais 6, 147-172.

Seber, G.A.F., 1982. The Estimation of Animal Abundance and Related Parameters, second ed. Macmillan, New York, USA, 654 pp.

Vincent, A.C.J., 1994. Seahorses exhibit conventional sex roles in mating competition, despite male pregnancy. Behaviour 128, 135-151.

Vincent, A.C.J., 1995. A role for daily greetings in maintaining seahorse pair bonds. Animal Behaviour 49, 258-260.

Wheeler, A., 1969. The Fishes of the British Isles and North West Europe. Macmillan, London, 529 pp.

Woods, C.M.C., Martin-Smith, K.M., 2004. Visible implant fluorescent elastomer tagging of the big-bellied seahorse, Hippocampus abdominalis. Fisheries Research 66, 363-371. 